\title{
Sentido e saúde na hermenêutica de H.- G. Gadamer
}

\author{
Maria Luísa Portocarrero
}

Em 1993, publicou Gadamer uma obra intitulada "Sobre a Latência da Saúde", onde evoca os diảlogos mantidos com o médico e filósofo Vitor von Weisaecker sobre a especificidade ética da praxis médica'. Nesta obra, Gadamer concretiza o seu modelo de uma hermenêutica prática, reflectindo sobre o modo como a condução das sociedades ocidentais contemporâneas pela ética da eficácia, própria de uma praxis guiada quase exclusivamente pelo primado das aplicações técnicas das novas ciências ${ }^{2}$, origina sérios problemas de ordem existencial como, por exemplo, os que dizem respeito ao âmbito da saúde. Estes são problemas que a ciência já não consegue resolver pelos seus próprios meios pois chocam com a autocompreensão que o homem tem de si mesmo ${ }^{3}$, provocando a meditação, a reflexão sobre a sua natureza e dignidade e, nomeadamente, o incremento da ética.

São as situações inéditas e complexas criadas pelos efeitos da penetração da tecnociência no âmbito da vida social humana a raiz desta nova ética que, defende valores como os de responsabilidade, solidariedade, precaução, dignidade humana, autonomia da pessoa e se propõe responder às transformações qualitativas do interagir humano, ocorridas no mundo da vida contemporâneo, fazendo-o por meio da necessidade de uma meditação sobre a intencionalidade do agir. Com esta demanda de ética tomamos finalmente consciência do modo como o ser humano alargou nos últimos anos, de modo inimaginável, o âmbito do seu poder fazer, tornando-se, pela primeira vez, perigoso para o próprio homem ${ }^{4}$.

É justamente o teor destas transformações uma das principais preocupações da hermenêutica de H.- G. Gadamer ${ }^{5}$, que não se cansa de nos lembrar que hoje o

1 Cf., Nomeadamente, H.- G. GADAMER, Ueber die Verborgenheil der Gesundheit. Aufsaetze und Vortraege, Frankfurt, 1993,111-130.Veja-se quanto a este assunto, M. BAPTISTA PEREIRA, "Meditação filosófica e medicina" in Revisia Filosófica de Coimbra, n. ${ }^{\circ} 21$ (2002), 3-80.

2 H.-G. GADAMER, op. cit., 134.

3 ID., 21-22.

4 Cf., neste sentido, P. RICOEUR «Postface au Temps de la responsabilité», in F. LENOIR, Le temps de la responsabilité, Paris, 1991, 249-270.

$s \quad C f$, quanto a estc assunto, M. L. PORTOCARRERO SILVA, «Filosofia, praxis e hermenêtica: a perspectiva de H.-G. Gadamer» in Revisıa Filosófica de Coimbra, n. ${ }^{\circ} 11$ (1997), 63-84. 
que é preciso pensar é a praxis; que a capacidade humana de meditação ou theoria faz parte integrante da praxis $^{6}$; que as novas formas de vida e relação social originadas pelo império da tecnociência conduzem a um perigoso esgotamento do simbólico ${ }^{7}$ e, enquanto tal, à manipulação do homem; que o homem manipulado é um homem alienado; que à natureza humana pertence uma forma simbólica, originária da praxis, que nada tem a ver com um agir conduzido pelo arbítrio egoísta ou por automatismos de ordem instintiva ou racional. É, pelo contrário, um tipo de agir guiado pela "escolha reflexiva, pela correcta antecipação e pela correcta ordenação sob fins comuns".

Reconhecer-se simbolicamente com outros no que é comum e não se reduz pelo facto de ser partilhado, comportar-se e actuar em solidariedade ${ }^{9}$, tal é a condição decisiva da praxis humana que, diferentemente da acção animal, é afã inibido, sabe manter presentes fins remotos a alcançar e deve sempre escolher ou decidir-se em favor de algo e contra $\operatorname{algo}^{10}$. A conclusão do silogismo e da reflexão prática, ensinou-nos Aristóteles, é a decisão, daí que no agir prático o homem não actue, apenas de acordo com o próprio arbítrio, mas, pelo contrário, de acordo com os demais, determinando em comum e através da interacção os assuntos comuns"

Ora, acontece que a ciência dissolve hoje todos os vínculos sociais (tradições, ritos, crenças, usos) e toda a ocasião de encontro inter-humano ao reclamar uma fundamentação puramente racional e operatória da vida social. Exclui, assim, toda a possibilidade de outras interpretações, praxis, culturas e valores que não sejam os da rentabilidade e da eficácia. É pois absolutamente necessário, rever os pressupostos do individualismo moderno e seus efeitos nos dias de hoje e, nomeadamente, a confusão que as actuais sociedades do bem estar, tecnologicamente assegurado, fazem entre saber agir e saber fazer. De outro modo, corremos o risco de a sociedade de especialistas e funcionários, em que vivemos elevar a figura do gestor técnico, frio e desapaixonado a modelo reitor da própria racionalidade prática.

$\mathrm{O}$ que aconteceria então? O maior perigo que Gadamer considera ameaçar a nossa civilização: a generalização do conformismo e da capacidade de adaptação, por outras palavras, a verdadeira anulação da liberdade e real autonomia dos indivíduos ${ }^{12}$.

Tudo isto significa, antes de mais, que o projecto de domínio, iniciado na Modernidade, como figura única da liberdade, se transforma na grande aporia do mundo contemporâneo. Que aporia é esta? Justamente aquela a que hoje procuram responder a eco e a bioética: a dos paradoxos de uma concepção de autonomia humana de natureza puramente individualista e operatória. Isto é, de uma autonomia que, excluindo todos o tipo de determinismos, nomeadamente, os da finitude e da relação, os do corpo e da morte, assenta exclusivamente na redução do saber à dimensão do poder e, como tal, na criação de um conceito de ciência, de pendor já não contemplativo mas profundamente especializado, seguro e provocador que deixa de lado, como não científica, toda uma outra forma mais meditativa, simbólica e hermenêutica de habitar e pensar o mundo. Este foi um verdadeiro acontecimento na história da humanidade, lembra-nos Gadamer, acontecimento que conferiu à

6 Cf., H.-G. GADAMER, Vernunft im Zeitalter der Wissenschaft. Aufsaetze, Frankfurt, 1976, $62-65 ; 82-83 ; 123-124$.

7 Cf., ID., 24-31.

8 Cf., ID., 63.

9 ID., 77.

10 ID., 69.

11 ID., 70.

12 Cf., ID., 58-60. 
ciência uma nova importância social e política e todo um novo estatuto à humanidade ${ }^{13}$.

Com efeito, "transformando-se no grandioso empreendimento de penetração em âmbitos desconhecidos, para os quais não é necessário nem um apoio humano nem um apoio divino"'14, a própria ciência foi perdendo o seu carácter académico e vinculador para se transformar num conjunto de tecnociências especializadas e o resultado é que a investigação, a todos os níveis em que hoje se exerce, está muito mais orientada para o poder agir com eficácia e não tanto para o saber viver em comum e poder interrogar. Daí o drama do mundo contemporâneo: a nossa consciência social e política não acompanhou o ritmo de desenvolvimento do progresso científico e tecnológico. Desaprendemos o discernimento, quer isto dizer, "não só o sentido prático para alcançar determinados fins, como a capacidade para os precisar e a responsabilidade a adoptar perante eles"15. A preocupação de meditar e conhecer o que interliga os homens foi-se, realmente, esbatendo perante a de dominar eficazmente e, de facto, nunca na história o homem foi tão longe na configuração dos possíveis que constituem o núcleo da sua liberdade, como nos dias de hoje! Podemos, com efeito, dizer que pela primeira vez, na história da humanidade, o homem dispõe de um saber que lhe permite exercer um poder sobre a natureza, sobre a vida e sobre a morte, isto é, sobre o que antigamente fugia à sua alçada e era considerado fatalidade ou, de modo determinista, uma sequência puramente causal de acontecimentos.

No entanto, constatamos hoje, no nosso dia a dia, que este poder, libertador e gerador de autonomia, tem-se revelado também extremamente ambíguo e perigoso. Desencadeia, pois, não só efeitos extremamente benéficos, dos quais depende a actual qualidade de vida do Ocidente, como dá origem a acções, cujas consequências perigosas têm pela primeira vez uma dimensão cósmica, muitas vezes irreversível. Daí a angústia e a desorientação do homem de hoje, incerto e inseguro perante as decisões que deve tomar, oscilando assim "entre os extremos de uma resistência emocional contra o novo e uma tendência não menos emocional para racionalizar todas as formas e aspectos da vida" ${ }^{\prime 6}$. O desenvolvimento científico e técnico que mais o assusta é o da biotecnologia e o da biomedicina pois este pode constituir uma séria ameaça para o futuro do humano. Irrompem então as grandes dúvidas, as angústias e inquietações: o que procuramos afinal com o desenvolvimento tecnológico: a luta contra a morte, a felicidade, a saúde perfeita, o bem- estar? Basta recordar, lembra-nos Gadamer, "o temor genético, a onda de susto que percorreu o mundo quando o colóquio CIBA - no qual se expuseram as possibilidades de realização no âmbito genético - foi conhecido pela opinião pública. Tratava-se aqui, de uma consciência ética? Por que razão nos haveria de assustar saber que era possível criar uma espécie de super-homem, por via genética, e que a sociedade poderia ser transformada em exércitos de abelhas obreiras?"1?.

Parece, pois, ter chegado a hora de responder à pergunta: haverá alguma possibilidade de reinterpretar, na época da tecnociência, a grande herança da sabedoria praxística clássica da humanidade? Nunca é tarde demais para a razão, lembra-nos Gadamer, pode até acontecer que uma solidariedade, acordada pela consciência do perigo, faça com que se manifeste o horizonte de uma verdadeira solidariedade ${ }^{18}$.

ID., Ueber die Verborgenheit der Gesundheit, 17.

14 Cf., ID., Lob der Theorie. Reden und Aufsaetze, Frankfurt, 1983, 34.

is ID., Ueber die Verborgenheit der Gesundheit, 68.

16 ID., 41.

17 ID., Vernunft im Zeitalter der Wissenschaft, 72.

18 ID., 75. 
O autor considera que são óbvios os sinais de mudança. O modo como a ciência entra hoje em conflito com a nossa consciência do valor humano faz-nos pensar nos limites de uma concepção meramente individualista e operatória de autonomia, aquela que subjaz à ética da eficácia. Não é por acaso que os gritos de alarme venham da própria ciência e que hoje, nomeadamente, a nova Medicina ${ }^{19}$ de carácter altamente especializado e dependente dos progressos das biotecnologias seja o real motivo das grandes dúvidas, perplexidades e meditações sobre o conceito de pessoa e o sentido da dignidade humana: "na realidade, a medicina é apenas um dos aspectos da vida social que nos levanta problemas através da ciência, da racionalização, da automatização e da especialização. A especialização (....) quando se ancilosa, para se transformar numa série de hábitos rígidos, converte-se num problema (...). Mas, na cultura científica moderna, conduziu a formas de vida que, em grande medida, automatizam a existência do indivíduo" ${ }^{20}$.

Não será exactamente no âmbito da praxis médica que irrompe a autonomia vulnerável e interdependente da pessoa humana, como limite de todo o individualismo e de toda a automatização própria da concepção meramente operatória de autonomia, e se confrontam, ainda, de modo agudo e complexo, a ética da vida humana, irremediavelmente simbólica e concreta, com as suas escalas de valores, hábitos, preferências e interesses próprios e a ética da eficácia própria das biotecnologias, que caracterizam, nomeadamente, a qualidade e os novos poderes da medicina? Não representará a praxis médica, habituada a lidar com a dimensão existencial do sofrimento, uma espécie particular de ciência prática, cujo conceito se perdeu com o pensamento moderno ${ }^{21}$. Não constituirá, por isso, a saúde hoje o espaço privilegiado de uma meditação ético-antropológica renovada, solidária do diálogo entre a Biologia, a Medicina, o Direito e a Religião e Filosofia?

Por outras palavras, porque será, de facto, que a questão da saúde se tornou nos dias de hoje uma questão tão central? Não será nela que se desvela, afinal, o essencial da condição humana, um ser que não se deixa reduzir a coisa, nem a mera capacidade operatória, mas que existe e é capaz no seio de uma permanente relação de cuidado, consigo mesmo, com o mundo e com os outros e, ainda, o que nesta relação de cuidado contraria toda a objectivação e manipulação, o trágico do sofrimento e da morte que inexplicavelmente continuam a existir, apesar de todo o progresso dos biopoderes? Por outra palavras, o que se retira claramente ao simulacro da perfeição realizável (um estado de permanente bem-estar ${ }^{22}$ ), própria da lógica da eficácia governada pelo ideal do poder para prever e dominar, obrigando-nos por isso mesmo a pensar mais e de um outro modo.

A experiência do corpo próprio e da saúde, enquanto condição fundamental da manutenção da abertura própria do cuidado humano, faz-nos hoje pensar muito seriamente nos limites do critério condutor da tecnociência, o da eficácia, nos seus pressupostos subjectivistas e na necessidade de uma forma de saber que origine um poder mais adequado à especificidade da natureza finita, temporal e eminentemente relacional do ser humano. Por isso, lembra-nos Gadamer, haveria que alargar a relação médico doente, que se encontra sob o signo do encontro, da interacção e da corporeidade, a toda a experiência das nossa próprias limitações ${ }^{23}$. Neste contexto, o autor medita e recorda os diálogos ocasionais, havidos com von Waisaecker, sobre a natureza da arte médica e, nomeadamente, o que através deles pôde aprender no que diz respeito à temática da saúde. Condição básica do sentido

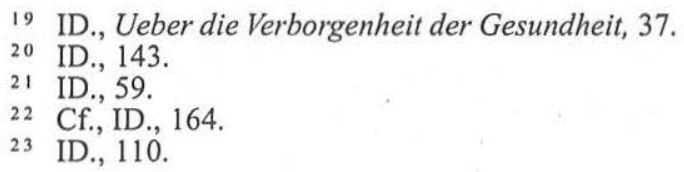


da vida humana, a saúde não é um objecto, nem uma coisa que a Medicina possa produzir. É um estado natural de equilíbrio ${ }^{24}$ que escapa, enquanto tal, a todo o critério científico de produção, bem como a toda a medida objectiva ou padronização ${ }^{25}$. Não chama a atenção por si mesma, nem é algo que se mostre à investigação. Existe, enquanto justamente se lhe esquiva. Por isso, não temos dela uma consciência permanente nem ela nos preocupa como a doença. A saúde não é algo que nos convide a um tratamento contínuo de nós mesmos. (...). Existe sob forma latente. Faz parte da milagrosa capacidade que tem todo o homem de se esquecer de $\mathrm{si}^{26}$, mantendo desse modo a abertura ao futuro, isto é, a novas possibilidades de ser si mesmo, por meio de uma frutuosa entrega às tarefas da vida e ao apelo do outro, que está aí e nos interpela ${ }^{27}$. Pelo contrário, lembra-nos Gadamer, o que se deixa objectivar e faz perceber, por contraste, a latência e o valor da saúde é a perturbação desta, os enigmas da doença, que necessitam de auxílio e cujo tratamento recusa, por sua vez, uma mera aplicação científica de regras. Requer, pelo contrário, uma forma de encontro e cuidado que excede em muito os progressos alcançados pelas técnicas modernas. Dele fazem parte, lembra-nos Gadamer, a mão que palpa, o ouvido fino, a palavra exacta, o olho atento do médico que procura ocultar-se por detrás de um olhar solícito" ${ }^{28}$. Por outras palavras, toda uma forma de praxis que exige, a solidariedade, a solicitude e excede, claro está, o mero cumprimento de regras seguras.

Daí o carácter exemplar que a medicina reveste para Gadamer: ela representa o modelo de uma ética dialógica, suscitada pelo encontro no sofrimento e por isso sempre situada entre arte (de curar) e técnica. De entre todas as ciências especializadas, lembra-nos o autor, ela é realmente a única que nunca poderá interpretar-se como uma mera técnica ${ }^{29}$. Nela o principal não é um fazer ou a produção planificada de algo artificial ${ }^{30}$. Pelo contrário, o que a arte de curar deve produzir é a saúde, quer dizer algo que é natural em si mesmo e diz respeito ao todo da vida. Logo, a sua forma de poder subordina-se ao curso natural da vida, consiste apenas em ajudar o doente a restabelecer o equilíbrio profundo que caracteriza a experiência relacional própria da saúde. A ciência médica (...) nada produz em absoluto, a saúde não é algo realizado pelo médico ${ }^{31}$, já que este não pode distanciar-se da sua obra tal como o faz qualquer artista relativamente à sua. O médico deve, ao contrário, contar expressamente com a maravilhosa capacidade que tem a vida para se restabelecer e se reequilibrar a si mesma. Neste sentido, a sua principal tarefa é a de contribuir para o restabelecimento da saúde" 32 : o verdadeiro médico, lembra-nos Gadamer, sabe que a sua profissão é simbólica, que não se limita a um mero fazer, sendo antes um proceder com compaixão e solicitude, do qual faz parte integrante o diálogo, enquanto núcleo fundamental de toda a terapia ${ }^{33}$. Só assim se estabelece, de facto, a relação de confiança que condiciona a prestação da ajuda que facilita ao ser vivo o seu regresso ao estado de bem-estar e abertura natural, a que chamamos saúde. "O médico clínico percebe-o muito bem. Sabe que se deve retirar para dirigir o paciente com uma mão cautelosa e deixar a sua natureza voltar

$\begin{array}{ll}24 & \text { ID., } 55 . \\ 25 & \text { ID., } 138 . \\ 26 & \text { ID., } 126 . \\ 27 & \text { ID., } 99 . \\ 28 & \text { ID., 129-130. } \\ 29 & \text { ID., } 59 . \\ 30 & \text { ID., 53. } \\ 31 & \text { ID., } 36 . \\ 32 & \text { ID., } 118 . \\ 33 & \text { ID., } 162 .\end{array}$


a si mesma"34. Tem clara consciência de que a medicina e o estudo dos estados de degenerescência da harmonia corporal constitutiva da saúde, não são de modo. algum um negócio de comerciantes. Toca, pelo contrário, em questões fílosóficas sérias, que dizem respeito aos fundamentos da ética, justamente aquelas que têm que ver com o sentido da existência, com a origem do mal e com a concepção de bem pressuposta na própria ideia de bem-estar característico da saúde e ainda no fim último para que este nos remete.

Condição da nossa humanidade, a saúde, hoje verdadeiro núcleo de uma ética da vida concreta, escapa, tal como o tempo, a toda a racionalização biomédica, sem no entanto poder recusar o seu carácter fundamentalmente auxiliar. Releva de uma harmonia intensa não criada pela técnica humana, mas profundamente oculta e, é preciso não esquecê-lo, encontra-se sempre num horizonte de perturbações e ameaças" 35 . É justamente o seu carácter recôndito que permite que o ser humano, que a possui, sem no entanto saber o que ela é, se realize na alegria de vida, numa espécie de bem-estar que se traduz no prazer de se sentir bem e de se mostrar empreendedor, aberto ao conhecimento e esquecido de si, mesmo quando experimenta fadigas e esforços. A saúde releva ainda de uma harmonia com o meio social e com o ambiente natural, que nos envolve, é o movimento da vida orientado para o todo e aberto ao futuro, aquele que nos faz estar aí no mundo com os outros, satisfeitos, activos e ocupados com os afazeres diários. Diz-se de forma indirecta, por meio do desejo de perseverar no ser, próprio da vida humana, daquele desejo que não é produto de fármacos, que nada é sem a realidade dos outros e que só a doença e a dor efectivamente perturbam, sendo estes, por essa mesma razão, o verdadeiro obstáculo a um pleno desenvolvimento. Quando estamos sãos lembra-nos Gadamer, entregamo-nos, ao que está aí diante de nós e todos sabemos até que ponto qualquer mal-estar, sobretudo a dor, perturba este nobre estado de alerta"36.

Percebemos, através desta importante reflexão hermenêutica de Gadamer sobre o enigma da saúde, que é o carácter relacional e inconsciente desta a verdadeira condição da liberdade solidária do ser humano. Logo que a autonomia humana radica no mistério da saúde, que não é um fim em si mesma, mas apenas a condição negativa do poder de abertura ao outro e à dimensão comunitária da vida. Poder esquecer-se de si, abrindo-se à comunidade da vida, estando presente a si mesmo pelo simples facto de estar com algo de outro ${ }^{37}$, tal é a condição da autonomia relacional para que aponta o carácter latente da saúde. Da sua preservação faz parte a forma de encobrimento própria do esquecer. Uma das grandes forças curativas da vida é a possibilidade de sucumbir, todas as noites, ao sono reparador que permite o esquecimento. Não poder esquecer-se de si, isso sim, representa uma grave doença"38.

Dizer-se-á, em jeito de conclusão, que o próprio âmbito da saúde é hoje profundamente manipulado pela técnica, que Gadamer desconhece as grandes transformações operadas na medicina contemporânea pelas aplicações do projecto genoma $^{39}$; que parte de uma relação intermitente do ser humano com uma medicina terapêutica e curativa; que, nos dias de hoje, a nova medicina de carácter preventivo

34 ID., 171.

35 ID., 142.

36 ID., 165.

37 ID., 168.

38 ID., 173-174.

39 Veja-se quanto a este assunto A BOUÉ, «L'apport des connaissances sur le génome humain dans les pratiques médicales» in G. TEBOUL, La vie, un énigme. Le génome humain en devenir, Paris, 2000, 75-83. 
e regenerativo ${ }^{40}$, fortemente apoiada no cruzamento de genética e informática, corre o risco de se tornar totalitária e vir a modelar o homem, de acordo com uma norma (genética) de saúde ${ }^{41}$. A este tipo de objecção poderemos responder do seguinte modo: a genética, último produto da técnica, dá-nos apenas uma norma limitativa do humano.

Sabemos é claro que o acesso sequencial ao genoma humano constitui a base de toda uma nova medicina, a medicina do futuro, e que o domínio médico e social das possibilidades de previsão do destino biológico dos indivíduos, actualmente em desenvolvimento, constitui um dos maiores problemas éticos da época contemporânea. Com a genética a prevenção torna-se individual, dependente das características do sujeito, logo, podendo claramente conduzir à obsessão da saúde ${ }^{42}$ e, nomeadamente, a estigmas e a discriminações ${ }^{43}$. «Dêem-me o genoma de um indivíduo e eu direi quem ele é», proclamava já o Nobel Walter Gilbert, escamoteando toda a interacção dos genes com o meio, isto é, o fenómeno da história e da cultura ${ }^{44}$. Uma utilização abusiva das características genéticas de um indivíduo pode mesmo vir a revolucionar os fundamentos da nossa sociedade, que tem repousado nos princípios de liberdade, igualdade e solidariedade. Além disso, é bom não esquecê-lo, é característico do perfil genético de uma pessoa conter indicações, mais ou menos fiáveis, quanto aos seus familiares: isto é quanto à sua família presente, passada e futura ${ }^{45}$. A noção de doença genética, aliada ao desenvolvimento das novas tecnologias, revoluciona assim os fundamentos da medicina curativa, podendo mesmo transformar o médico menos consciente em agente de uma nova organização social. Com efeito, a despistagem genética associada ao culto biológico da saúde e da perfeição corpórea ${ }^{46}$ pode não só conduzir a perigosas formas de discriminação $0^{47}$, como a uma transformação da essência tradicionalmente curativa e solidária da medicina. Acontecerá também que a predição de uma certa predisposição, que não se sabe se virá ou não a revelar-se, venha a colocar pessoas, ainda de perfeita saúde, em estado de profunda falta de liberdade, o mesmo é dizer, de falta de equilíbrio.

Perfila-se, deste modo a terrível sombra de uma nova eugenia e ressurge o fantasma do determinismo biológico do comportamento humano. Assimilada ao seu tipo genético a pessoa pode acabar por perder toda a dimensão relacional que the proporciona o sentimento de bem-estar, de que nos falava Gadamer, correndo mesmo o risco de exclusão. Para a genética, aliás, não o esqueçamos, a pessoa não existe,

40 Cf., neste sentido, A. KAHN, Os caminhos da medicina no séc XXI. Genes e homens, trad. Lisboa, 1999.

41 DAVID LE BRETON, L'adieu au corps, Paris, 1999, 114.

42 Cf., L. SFEZ, "La symbolique utopique de la santé parfaite», in T. FERENCZI, Changer la vie? Paris, 2001, 86.

43 Cf., "Os genes mostram perfeitamente que somos muito diferentes uns dos outros e que as nossas susceptibilidades às doenças nos são próprias. Alguns pensam, muito provavelmente; que chegará talvez o momento em que podemos encontrar certos marcadores biológicos ou certas características do nosso ADN e associá-los razoavelmente a características comportamentais, até mesmo a aptidões". A. KAHN, Os Caminhos da medicina,172; ID., Et l'homme dans tout ça?, 271 ss.

${ }^{44}$ L. SFEZ, «La symbolique utopique de la santé parfaite», 86.

45 Cf., G. HOTTOIS, Essais de philosophie bioéthique et biopolitique Paris, 1999, 97.

$46 \mathrm{Cf}$., "Observons aussi en conséquence la substitution de la notion de perfection à celle de santé. Ce n'est plus la santé de nos successeurs qui est visé, mais déjà pour nous - mêmes, pour notre temps. Déjà, la médecine présente quelques prétentions à la perfection (...). Ce mouvement naturel à une partie de la médecine s'amplifie aujourd'hui au contact de la génétique, renforçant la médicalisation de la société et le rôle de la médecine dans le contrôle de la déviance» L. SFEZ, La santé parfaite. Critique d'une nouvelle utopie, Paris, 1995. 
apenas o corpo objecto, entendido como um mecanismo impessoal resultante da interacção entre as moléculas ${ }^{48}$.

É claro que são grandes os riscos de a nova medicina se transformar em engenharia biomédica. Muito em breve, será possível desactivar um gene, combiná-lo com outros e criar indivíduos na base da ideologia do geneticamente correcto. Será também impossível não colocar, nesta altura, sérias questões de ordem filosófica e ética. Quer isto dizer que, graças ao génio genético, a medicina transforma-se, neste século, no verdadeiro palco de interesses sociais, políticos, económiços e sobretudo filosóficos. Pensamos, por isso, que as novas capacidades de prevenção, predição e manipulação do destino biológico dos indivíduos tornarão ainda mais exigente e responsável a tarefa ética e hermenêutica da pessoa que, apesar de tudo, é e será sempre o médico. Vejamos como: se, de facto, a genética lhe permite novos poderes sobre o homem, pelo facto de identificar e controlar os caracteres hereditários contidos nas sụas células, é preciso não esquecer, como nos lembra H. Atlan, que estes enunciam, na maioria dos casos, apenas uma probabilidade de ocorrência ${ }^{49}$. A descoberta do gene de tal ou tal predisposição é apenas a de uma correlação estatística entre marcadores genéticos e uma certa frequência da doença em determinadas famílias e circunstâncias. O conhecimento genético, tal como existe hoje, é fundamentalmente parcial, complexo e baseado em probabilidades ${ }^{50}$. Permite, no entanto, a adopção de medidas preventivas que permitam contrariar ou atenuar as consequências de uma doença genética. Suscita, por isso, inúmeros problemas éticos e toda uma reflexão sobre a condição humana e seus vínculos fundamentais. Estamos, pois, muito longe de uma predição segura e rigorosa, não somente em virtude das incertezas relacionadas com a interacção de vários factores ambientais na sequência genética, como em virtude do carácter imprevisível do comportamento da pessoa visada e do uso que esta faz da sua liberdade.

Existe assim para a própria medicina todo um trabalho de semântica genética e hermenêutica das situações concretas, que exigem deliberação, a realizar, antes de todo e qualquer arrebatamento simplista pela vertigem do novo mito do século XXI, o da saúde geneticamente perfeita. Deste trabalho, fará parte integrante toda uma nova formação teórica, de vocação já não construtiva e operatória, mas fundamentalmente antropológica e axiológica, que permita a disposição para a responsabilidade, para a prudência no aconselhamento genético e, nomeadamente, o cultivo da solidariedade. Com efeito, com a previsível generalização dos testes genéticos, estará alguém totalmente isento de genes mutantes predispondo à doença? Poderá, alguém dizer que é absolutamente são, imune à doença e ao sofrimento? Os novos conhecimentos genéticos obrigam-nos a rever a própria ideia de que os genes são de uma pessoa só e que as decisões a tomar são do âmbito de uma autonomia absolutamente privada.

É o mundo das relações inter-humanas, o significado do sofrimento na comunidade de vida do homem relacional, a reflexão sobre os fins da medicina e sua relação com os fins da vida, que a nova medicina, altamente especializada e operatória obrigará ainda a privilegiar; nomeadamente, o papel da palavra preditiva que, narrando, anuncia e, ao fazê-lo, mexe com projectos, transforma caminhos de vida, provoca talvez mais angústia do que remédio, exigindo por isso o diálogo, verdadeira condição de uma fundamental re-simbolização dos vínculos eminentemente comunitários e sociais que entretecem a condição sempre esperançada e vulnerável do existir humano.

Cf., T. WILKIE, Projecto genoma. Um conhecimento perigoso, trad., Rio de Janeiro, 1994, $11 \mathrm{ss}$.

49 H. ATLAN, «Dialogue 2. Une médecine en blouse blanche» in SAMY ABTROUN (ed), Vous avez dit santé? Paris, 2001, 30-31.

50 Cf., A. JACQUARD, A. KAHN, L'avenir n'est pas écrit, Paris, 2001, 175-176. 